\title{
EFFECT OF POST CURE TREATMENTS ON RESIDUAL MONOMER CONTENT OF TWO COMMERCIALLY AVAILABLE HEAT CURE DENTURE BASE RESINS. AN IN-VITRO STUDY
}

\section{Dr Joy PT *}

Assistant Professor, Dept. of Prosthodontics, Government Dental College, Thrissur. *Corresponding Author
Dr Mehul R Mahesh Dr V.K Zahida

Associate Professor, Dept. of Prosthodontics, Government Dental College, Thrissur

Former Professor \& Head, Dept. of Prosthodontics, Govt. Dental college, Calicut

\section{Dr Gilsa K. Vasunni}

\section{Dr Lylajam S}

Principal, Govt. Dental college , Calicut

Professor \&Head, Dept. of Prosthodontics, Government Dental College, Thrissur

\section{ABSTRACT}

The presence of Residual monomer content in processed dentures is not desirable. Different methods are used for reducing the residual monomer content after processing. In the present study the effects of two post cure treatments (water immersion and additional curing cycle) on the residual monomer content of two commonly used denture base resins (Acralyn $\mathrm{H}$ and Trevalon $\mathrm{Hi}$ ) were evaluated by using gas chromatography. Study concluded that both water immersion for one day at room temperature and additional curing cycle reduced the residual monomer content in both brands which was initially high after processing.

\section{KEYWORDS : Residual monomer, Post cure treatments, Gas chromatography, Denture base resins}

\section{INTRODUCTION}

The residual monomer in the processed dentures can leach out from the resin and has been known to cause mucosal irritation, inflammation and allergic reactions in tissues adjacent to dentures. Different methods are used for reducing the residual monomer content after processing. In the present study the effects of two post cure treatments (water immersion and additional curing cycle) on the residual monomer content of two commonly used denture base resins (Acralyn $\mathrm{H}$ and Trevalon Hi) were evaluated by using gas chromatography.

\section{AIMS AND OBJECTIVES}

The present study aims,

1. To determine the effect of post cure treatment on the residual monomer content by placing the polymerized samples in water at room temperature for 1 day.

2. To determine the effect of post cure treatment on the residual monomer content by placing the polymerized samples in water at room temperature for 1 day followed by an additional curing cycle.

\section{MATERIALS AND METHODS}

Two heat cure denture base resins were used in this study.

(1) Trevalon Hi-high impact denture material

(2) Acralyn ' $\mathrm{H}$ ' - cross linked denture base material

Materials, powder - liquid (P/L) ratio and manufacturers are listed below:

\begin{tabular}{|l|l|l|}
\hline Materials & P/L Ratio & Manufacturers \\
\hline Trevalon Hi & $25 \mathrm{~g} / \mathrm{lml}$ & $\begin{array}{l}\text { Dentsply India Pvt } \\
\text { Ltd, New Delhi- } \\
110017\end{array}$ \\
& $3: 1 \mathrm{v} / \mathrm{v}$ & $\begin{array}{l}\text { Asian acrylates, } \\
\text { Mumbai, India - } \\
400064 .\end{array}$ \\
\hline
\end{tabular}

Two curing cycles were employed for this study as described below:

\begin{tabular}{|l|l|}
\hline $\begin{array}{l}\text { Cycle I } \\
\text { Long curing } \\
\text { cycle (L) }\end{array}$ & $\begin{array}{l}\text { Processing denture base resin in a } \\
\text { constant temperature water bath at 74o C } \\
\text { for 9 hours with no terminal boiling } \\
\text { treatment. }\end{array}$ \\
\hline
\end{tabular}

\begin{tabular}{|l|l|}
\hline Cycle II & Involves processing the resin at 74 o C for \\
Short curing & 2 hours and increasing the temperature of \\
cycle & the water bath to 100 oC and processing \\
(S) & for 1 hour. \\
\hline
\end{tabular}

Specimen Preparation

A steel disc of diameter $30 \mathrm{~mm}$ and thickness $3 \mathrm{~mm}$ was prepared and Elastomeric impression of this steel disc was made using addition silicone impression material. (Reprosil, Dentsply). This was used to make 12 wax specimens using Modeling wax (Hindustan Modeling wax No 2, Hindustan dental products, Hyderabad, India).

The specimens were invested in denture flasks using class III dental stone (Kalstone, Kalabhai, Mumbai, India ). Dewaxing was done by immersing the flasks in boiling water for 5 minutes. Manipulation and packing of the 2 resins (Trevalon $\mathrm{Hi}$ and Acralyn H) according to standard practice was done and flasks were immersed in thermostatically controlled water bath (EWL-5501 Acryliser, Kavo company, Japan). The two curing cycles as described above were employed. The flasks were bench cooled before deflasking.

Specimens were trimmed of flash and hand polished using 600 grit silicon carbide paper and individually measured by use of a vernier caliper.

A total of 12 discs were made (6 discs of Trevalon Hi and 6 discs of Acralyn H) Of these 6 discs, 3 discs were made by short curing cycle, "S" and other 3 discs by long curing cycle, "L". Each of these three discs were again categorized into one each for measuring the residual monomer as follows,

1. Immediately after processing the specimen

2. Immersion in water for 1 day $(\mathrm{W})$ at room temperature.

3. Immersion in water for 1 day followed by an additional curing cycle.

Immersion of resin discs in water was done to simulate the storage of denture in water for one day before delivery.

Additional curing cycle was given to mimic the processing of permanent denture base and relining procedure. 
Six samples were made from each disc of the above mentioned categories and samples were distributed as below \begin{tabular}{|l|l|l|}
\hline Group 1 - AL & Group 2 - ALW & Group 3 - ALW + L \\
\hline
\end{tabular} Group 4 - AS Group 7 - TL Group 5 - ASW Group 6 - ASW+ S \begin{tabular}{|l|l|l|} 
& Group 11 -TSW & Group 12- TSW + S \\
\hline
\end{tabular}

AL - Acralyn, Long curing cycle

ALW -Acralyn, Long curing cycle, Immersed in water for 1 day.

ALW + L -Acralyn, Long cured, immersed in water with additional long cure

AS - Acralyn, short curing cycle

ASW - Acralyn, Short curing cycle, Immersed in water for 1 day.

ASW + S -Acralyn, Short cured, immersed in water with an additional short cure

TL -Trevalon, Long curing cycle

TLW -Trevalon, Long curing cycle, Immersed in water for 1 day.

TLW +L - Trevalon, Long cured,immersed in water with an additional long cure

TS $\quad$-Trevalon, Short curing cycle

TSW -Trevalon, Short curing cycle, Immersed in water for 1 day

TSW + S - Trevalon, Short cure,Immersed in water with an additional short cure.

Method Of Determining The Residual Monomer

The residual monomer was analyzed using gas chromato graphy by the method described by Sadamori et $\mathrm{al}^{1}$. Each acrylic specimen was cut in to small pieces. $5 \mathrm{ml}$ of methyl ethyl ketone was added into individual glass test tubes, each of which had a resin sample of about $0.2 \mathrm{gm}$ in mass, which were then kept in dark place at $4^{\circ} \mathrm{C}$ for 96 hours 10 micro liter of p-xylene was then added as an internal standard ( $2 \mu \mathrm{l}$ per $\mathrm{ml}$ ) and centrifuged at $2000 \mathrm{rpm}$ for 15 minutes. The supernatant was then transferred in to a vial awaiting analysis using gas chromatography with a flame ionization detector.

Gas chromatography was performed with Perkin Elmer Autosystem Gas chromatograph equipped with total chrome software.

The amount of methyl methacrylate was determined using standard calibration graph prepared by plotting peaks

against known amounts of MMA. The residual monomer of each type of resin was given as percentage by mass of the specimen. The results were statistically analysed using MANOVA and Scheffe Test

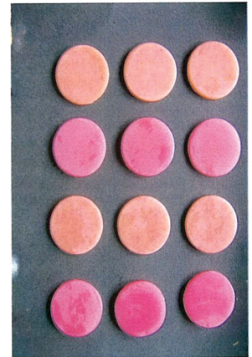

ACRYLIC DISCS OF TREVALON \& ACRALYN

Figure 1

RESULTS

Percentage Of Residual Monomer

Table I Acralyn Brand

\begin{tabular}{|l|l|l|l|l|l|l|}
\hline GROUP & $\begin{array}{l}\text { (1) } \\
\text { AL }\end{array}$ & $\begin{array}{l}\text { (2) } \\
\text { ALW }\end{array}$ & $\begin{array}{l}\text { (3) } \\
\text { ALW +L }\end{array}$ & $\begin{array}{l}\text { A) } \\
\text { AS }\end{array}$ & $\begin{array}{l}(5) \\
\text { ASW }\end{array}$ & ASW +S \\
\hline Specimen 1 & 2.21 & 1.91 & 1.78 & 1.19 & 1.01 & 0.73 \\
\hline Specimen 2 & 2.32 & 1.98 & 1.75 & 1.08 & 0.98 & 0.71 \\
\hline Specimen 3 & 2.28 & 1.89 & 1.68 & 1.18 & 0.95 & 0.68 \\
\hline Specimen 4 & 2.18 & 1.86 & 1.69 & 1.13 & 0.92 & 0.69 \\
\hline Specimen 5 & 2.25 & 2.06 & 1.72 & 1.16 & 0.96 & 0.73 \\
\hline Specimen 6 & 2.31 & 1.93 & 1.74 & 1.12 & 1.06 & 0.67 \\
\hline Mean Value & 2.258 & 1.938 & 1.726 & 1.143 & 0.98 & 0.7016 \\
\hline
\end{tabular}

Table II Trevalon Brand

\begin{tabular}{|l|l|l|l|l|l|l|}
\hline GROUP & $\begin{array}{l}(7) \\
\text { TL }\end{array}$ & $\begin{array}{l}(\mathbf{8}) \\
\text { TLW }\end{array}$ & $\begin{array}{l}\text { TL) } \\
\text { TLL }\end{array}$ & $\begin{array}{l}\text { TS } \\
\text { TS }\end{array}$ & $\begin{array}{l}\text { (1) } \\
\text { TSW }\end{array}$ & TSW+S \\
\hline Specimen 1 & 2.91 & 2.47 & 1.93 & 1.34 & 1.18 & 0.86 \\
\hline Specimen 2 & 2.89 & 2.48 & 1.91 & 1.45 & 1.20 & 0.75 \\
\hline Specimen 3 & 2.90 & 2.52 & 1.89 & 1.37 & 1.16 & 0.78 \\
\hline Specimen 4 & 2.98 & 2.42 & 1.94 & 1.42 & 1.22 & 0.83 \\
\hline Specimen 5 & 2.86 & 2.40 & 1.87 & 1.40 & 1.16 & 0.82 \\
\hline Specimen 6 & 2.94 & 2.45 & 1.79 & 1.39 & 1.21 & 0.78 \\
\hline Mean Value & 2.913 & 2.456 & 1.888 & 1.390 & 1.188 & 0.803 \\
\hline
\end{tabular}

Table III Mannova Values lbrand, 2 Cycle, 3 Base

\begin{tabular}{|l|l|l|l|l|l|l|l|}
\hline & dF Effect & MS Effect & dF Error & MS Error & F & p- level & \\
\hline Brand & 1 & 1.798672 & 60 & 0.002071 & 868.6906 & 0 & Significant \\
\hline Cycle & 1 & 24.29045 & 60 & 0.002071 & 11731.37 & 0 & Significant \\
\hline Base & 2 & 2.526539 & 60 & 0.002071 & 1220.223 & 0 & Significant \\
\hline Brand x Cycle & 1 & 0.299022 & 60 & 0.002071 & 144.4164 & $1.3 E-17$ & Significant \\
\hline Brand x base & 2 & 0.165239 & 60 & 0.002071 & 79.80413 & $1.24 E-17$ & Significant \\
\hline Brand x cycle & 2 & 0.113217 & 60 & 0.002071 & 54.67937 & $3.02 E-14$ & Significant \\
\hline Brand x cycle $x$ base & 2 & 0.047272 & 60 & 0.002071 & 22.83069 & $4.24 E-08$ & Significant \\
\hline
\end{tabular}

Table Iv Scheffe Test, Variable Rm(dat.sta) Probabilities For Post Hoc Tests Interaction: 1 × 2 × 3

\begin{tabular}{|c|c|c|c|c|c|c|c|c|c|c|c|c|c|}
\hline Average RM & & \begin{tabular}{|l|}
$(1)$ \\
2.258
\end{tabular} & \begin{tabular}{|l|}
$(2)$ \\
1.938
\end{tabular} & \begin{tabular}{|l} 
(3) \\
1.727
\end{tabular} & \begin{tabular}{|l}
$(4)$ \\
1.143
\end{tabular} & \begin{tabular}{|l|}
$(5)$ \\
.980
\end{tabular} & \begin{tabular}{|l|}
$(6)$ \\
.702
\end{tabular} & \begin{tabular}{|l|}
$(7)$ \\
2.913
\end{tabular} & \begin{tabular}{|l|}
$(8)$ \\
2.457
\end{tabular} & \begin{tabular}{|l|}
$(9)$ \\
1.888
\end{tabular} & \begin{tabular}{|l|}
$(10)$ \\
1.395
\end{tabular} & \begin{tabular}{|l}
$(11)$ \\
1.188
\end{tabular} & $\begin{array}{l}\text { (12) } \\
.803\end{array}$ \\
\hline Ācralyn long & I (1) & & 0.00 & 0.00 & 0.00 & 0.00 & 0.00 & 0.00 & 0.00 & 0.00 & 0.00 & 0.00 & 0.00 \\
\hline Âcralyn long & $\mathrm{I}+\mathrm{W}(2)$ & 0.00 & & 0.00 & 0.00 & 0.00 & 0.00 & 0.00 & 0.00 & 0.98 & 0.00 & 0.00 & 0.00 \\
\hline Acralyn long & $\mathrm{I}+\mathrm{W}+\mathrm{I}(3)$ & 0.00 & 0.00 & & 0.00 & 0.00 & 0.00 & 0.00 & 0.00 & 0.00 & 0.00 & 0.00 & 0.00 \\
\hline \begin{tabular}{|l} 
Acralyn short \\
\end{tabular} & I (4) & 0.00 & 0.00 & 0.00 & & 0.00 & 0.00 & 0.00 & 0.00 & 0.00 & 0.00 & 0.99 & 0.00 \\
\hline Acralyn short & $\mathrm{I}+\mathrm{W}(5)$ & 0.00 & 0.00 & 0.00 & 0.00 & & 0.00 & 0.00 & 0.00 & 0.00 & 0.00 & 0.00 & 0.00 \\
\hline Acralyn short & $\mathrm{I}+\mathrm{W}+\mathrm{I}(6)$ & 0.00 & 0.00 & 0.00 & 0.00 & 0.00 & & 0.00 & 0.00 & 0.00 & 0.00 & 0.00 & 0.21 \\
\hline Trevalon long & I (7) & 0.00 & 0.00 & 0.00 & 0.00 & 0.00 & 0.00 & & 0.00 & 0.00 & 0.00 & 0.00 & 0.00 \\
\hline Trevalon long & $\mathrm{I}+\mathrm{W}(8)$ & 0.00 & 0.00 & 0.00 & 0.00 & 0.00 & 0.00 & 0.00 & & 0.00 & 0.00 & 0.00 & 0.00 \\
\hline Trevalon long & $\mathrm{I}+\mathrm{W}+\mathrm{I}(9)$ & 0.00 & 0.98 & 0.00 & 0.00 & 0.00 & 0.00 & 0.00 & 0.00 & & 0.00 & 0.00 & 0.00 \\
\hline Trevalon short & I (10) & 0.00 & 0.00 & 0.00 & 0.00 & 0.00 & 0.00 & 0.00 & 0.00 & 0.00 & & 0.00 & 0.00 \\
\hline
\end{tabular}




\begin{tabular}{|l|l|l|l|l|l|l|l|l|l|l|l|l|l|}
\hline Trevalon short & $\mathrm{I}+\mathrm{W}(\mathrm{l})$ & 0.00 & 0.00 & 0.00 & 0.99 & 0.00 & 0.00 & 0.00 & 0.00 & 0.00 & 0.00 & & 0.00 \\
\hline Trevalon short & $\mathrm{I}+\mathrm{W}+\mathrm{I}(12)$ & 0.00 & 0.00 & 0.00 & 0.00 & 0.00 & 0.21 & 0.00 & 0.00 & 0.00 & 0.00 & 0.00 & \\
\hline
\end{tabular}

GRAPH - I

Percentage of residual monomer of Acralyn and Trevalon Groups

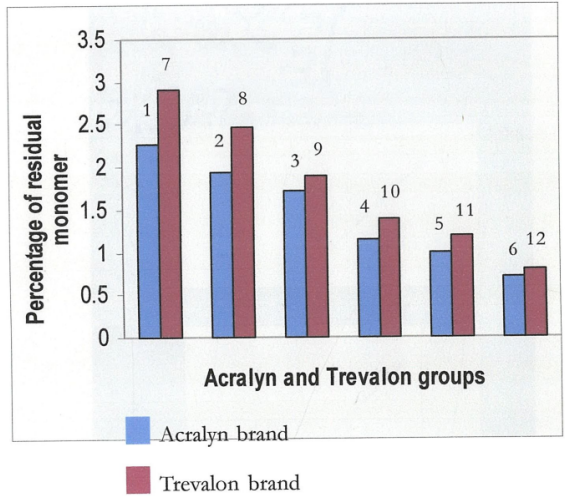

GRAPH-2

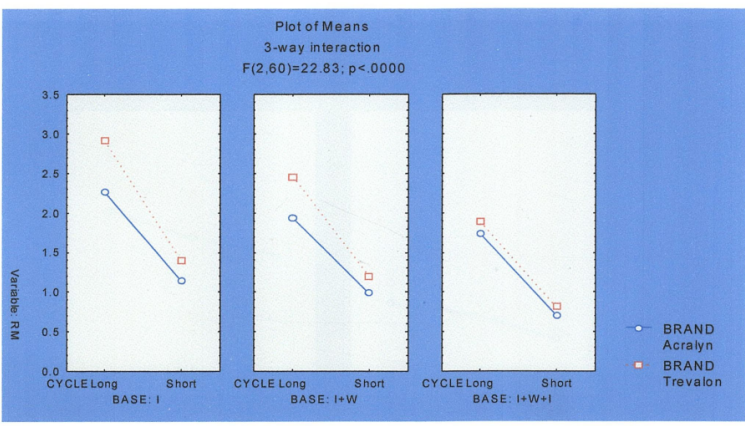

GRAPH-3

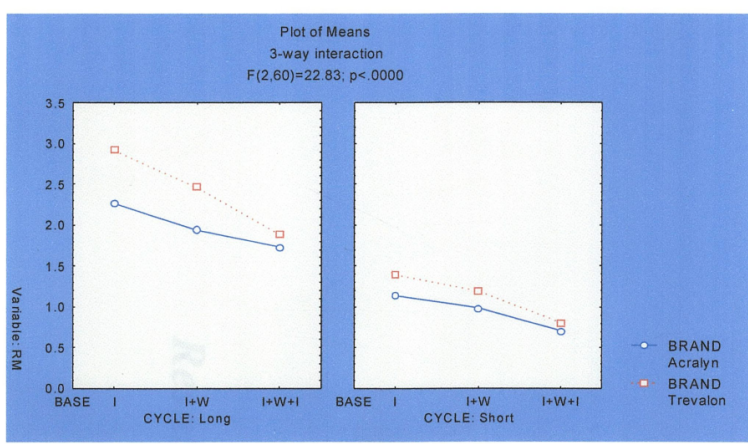

\section{In Acralyn Brand}

1. The highest residual monomer content was shown by specimens of group 1-AL in Table I (Mean value 2.258). The lowest residual monomer content was shown by specimens of group $6-\overline{A S W}+\mathrm{S}($ Mean value 0.7016$)$. So the reduction in residual monomer content was 1.557 .

2. Within the long curing cycle groups, specimens of group 1 AL showed highest residual monomer content. Lowest residual monomer content was shown by group 3 ALW+L (Mean value 1.726), So there was a reduction of residual monomer content by 0.532 .
When group 2 ALW (Mean value 1.938) was compared with group $\mathrm{AL}$, there was a reduction of 0.32 in the residual monomer content. When group3 ALW+L was compared with group $2 \mathrm{ALW}$, the reduction was 0.21 .

In short, when long curing cycles are employed for Acralyn specimens the highest residual monomer content was shown initially after processing, and it decreased with post cure treatments.

3. Within the short curing cycle groups, specimens of group 4 AS showed highest residual monomer content.(Mean value 1.143).Group $6 \mathrm{ASW}+\mathrm{S}$ showed lowest residual monomer content.(Mean value 0.7016).The reduction in residual monomer content was 0.44

When the group 5ASW (mean value 0.98) was compared with group $4 \mathrm{AS}$, There was a reduction in residual monomer content of 0.16 . When the group $6 \mathrm{ASW}+\mathrm{S}$ was compared with the group 5ASW, the reduction in residual monomer content was 0.28 .

Therefore, when short curing cycles were employed, the residual monomer content was high initially after processing and it decreased with post cure treatment.

4. When the long curing groups and short curing groups were compared, group AS showed a reduction of 1.12 than group AL. Group ASW showed a reduction of 0.95 than group ALW. Group ASW+S showed a reduction of 1.02 than ALW+L. So the specimens cured by short curing cycles showed low residual monomer content than specimens cured by long curing cycles.

5. Statistical analysis showed that all the groups were significantly different within the Acralyn brand.

\section{In Trevalon Brand,}

1. The highest residual monomer content was shown by the specimens of group 7- TL in Table V(Mean value 2.913). The lowest residual monomer content was shown by specimens of group 12- TSW $+\mathrm{S}$ (Mean value 0.803 ). The reduction in residual monomer content was 2.11.

2. Within the long curing cycle groups, specimens of group 7 -TL showed highest residual monomer content Lowest residual monomer content was shown by specimens of group 9- TLW+L (Mean value 1.888).So there ' was a reduction of 1.025 .

When the group 8 -TLW (Mean value 2.456) was compared with group 7-TL, there was reduction of 0.459 in residual monomer content. When group9- TLW+L was compared with group 8 -TLW, the reduction was 0.573.Therefore, when long curing cycles were employed the highest residual monomer content was shown initially after processing. Then it decreased with post cure treatments

3. Within the short curing cycle groups, specimens of group 10TS (Mean value 1.390) showed highest residual monomer content. Group 12-TSW+S showed lowest residual monomer content (Mean value 0.803). So there was a reduction of 0.587 .

When the group 11-TSW(Mean value 1.188)was compared with group TS, the reduction was 0.202 .When the group 12 $-\mathrm{TSW}+\mathrm{S}$ (Mean value 0.803 )was compared with group 11 TSW the reduction was 0.385 .Therefore, when the short curing cycles were employed, residual monomer content was high initially then it decreased with post cure treatments. 
4. When the long curing groups and short curing groups were compared groupl0 -TS showed a reduction of 1.523 than group 7-TL.Group TSW showed a reduction of 1.268 than group 8-TLW.Then groupl2-TSW+S showed a reduction of 1.085 than group 9-TLW+L.So specimens cured by short curing cycles showed a low residual monomer than specimens cured by long curing cycles.

6. Statistical analysis showed that all the groups were significantly different within the Trevalon brand.

III. When the two brands were compared, Acralyn specimens showed lower residual content than Trevalon specimens in all conditions. When all the groups in both Acralyn and Trevalon brands were analysed with each other by SCHEFFE' $\mathrm{S}$ test, the following inferences were observed, There was statistically significant difference between all the groups except,

1. Between group 2-ALW and group 9-TLW+L(Pvalue0.98).

2. Between group 4-AS and group 1 1-TSW (Pvalue 0.99).

3. Between group $6-\mathrm{ASW}+\mathrm{S}$ and group $12-\mathrm{TSW}+\mathrm{S}(\mathrm{P}$ value .21).

\section{DISCUSSION}

The purpose of this study was to evaluate the effect of post cure treatments namely water immersion at room temperature for one day and an additional curing cycle on the residual monomer content of two commonly used heat cure denture base resins, Acralyn $\mathrm{H}$ and Trevalon Hi processed by two different curing cycles (short and long curing cycles) The conversion of monomer to polymer during the polymerization is not complete and residual monomers are invariably left in the denture base resin.

Methods for reducing the residual monomer content include microwave polymerization, increasing the time and temperature of polymerization, and post cure treatments like water immersion, additional curing cycle and surface conditioning of denture like polishing.

Different methods have been developed to determine the levels of residual methyl methacrylate monomer like chemical methods, infrared spectroscopy, high performance liquid chromatography and gas chromatography. Gas chromatogr aphy, which is a precise and simple method to determine the residual monomer content, was utilized in this study.

Results showed that in both brands the residual monomer content was initially high after processing but decreased with post cure treatments. Water immersion for one day at room temperature significantly decreased the residual monomer content. This is in confirmation with the findings of Tsuchiya et $\mathrm{al}^{2}$, Vallittu et $\mathrm{al}^{3}$ etc. The possible explanation is as follows: There are two types of residual monomers in the polymerized resin, extractable and non extractable as postulated by Smith and Bains ${ }^{4}$. Extractable residual monomer is associated with the surface of the material. This is absent in the interior of the material because the polymerization has proceeded further as a consequence of the higher temperature reached there on account of exothermic nature of the polymerization reaction .The non extractable monomer may perhaps consists of molecules trapped in some way in the long polymer molecules Water immersion causes leaching out of this extractable monomer and hence the reduction in the residual monomer content

The polymerization reaction is not complete within the curing cycle. It further proceeds at a slower rate due to the presence of free radicals remaining in the resin. This continuous polymerization phenomenon can also be a contributing factor in reducing the residual monomer content after water immersion. The reactivity of oxygen with free radicals is higher than that with monomers. Hence the polymerization reaction is inhibited by oxygen. Expelling oxygen by immersing the resin in water probably diminished the oxygen effects and results in a higher degree of polymerization.

The effect of additional curing cycle was also evaluated in this study. The results showed that additional curing cycle also reduced the residual monomer content. Similar results were obtained for Nunes de Mello et $\mathrm{al}^{5}$, Shim et al etc ${ }^{6}$.

The additional curing cycle may have two effects on the residual monomer content:

1. The heat from the additional curing cycle may have promoted the diffusion of unreacted monomer molecules to the surface and their subsequent volatilization causing the decrease in the residual monomer content

2. The additional curing cycle also promotes further polymerization of the residual monomer and thereby decreasing its content in the resin.

Results indicated that the Acralyn specimens showed lower values of residual monomer content than Trevalon brands. This can be due to the difference in concentrations of initiator, activator, cross linking agent and inhibitor.

Jerolimov et al, in $1989^{7}$, had demonstrated the influence of benzoyl peroxide and tertiary amine (chemical activator) on the degree of polymerization. They found that higher the benzoyl peroxide content lower is the residual monomer and higher the tertiary amine content higher is the residual monomer.

It is also possible that the variation in the amounts of inhibitor and crossing linking agents may influence the polymeriz ation. Cross linked resins on polymerization join polymer molecules in all directions forming a network of polymer molecules. Once such network starts forming it grows into a macro molecule trapping increased amount of monomer which could not used up by the polymer molecules already joined, and therefore such molecule of monomer remain residual and trapped within the network polymer macro molecule. It is possible that the amount of crosslinking agent can be higher in Trevalon Hi brand and therefore the residual monomer content will be also higher than Acralyn brand.

Mixing ratio between powder and liquid of each material may also have an effect on the residual monomer content. Polymer and monomer were mixed according to manufacturer's instruction ie $25 \mathrm{gm}$ powder: $11 \mathrm{ml}$ monomer for Trevalon and 3:1 by volume for Acralyn. This disparity in the polymer monomer ratio between the brands may be a contributing factor to the difference in the residual monomer content.

There was no significant difference between the two brands in residual monomer content when the specimens were processed by short curing cycle followed by water immersion and additional short curing cycle. Acralyn specimens showed similar residual monomer levels to Trevalon specimens in two conditions where the short cured Acralyn specimens were compared with Trevalon specimens which were processed by short curing cycle followed by water immersion and when long cured Acralyn specimens, immersed in water were compared with Trevalon specimens which were long cured, water immersed and received additional long curing cycle.

According to ISO specifications $1567^{8}$ the maximum residual monomer content of heat cure denture base resin should not exceed $2.2 \%$ by wt. In the present study only Trevalon specimens which were processed by long curing cycle without post curing treatments and Trevalon specimens processed by long curing cycle and water immersion showed higher residual monomer content than recommended. 
It is also worth mentioning that while selecting an optimum curing cycle apart from the residual monomer content other properties also have to be considered like strength of the resin, porosity etc. So an optimum curing cycle which allows the resin to be free of porosity, strong and with lowest residual monomer content as possible should be selected.

\section{CONCLUSION}

Within the limitations of the study the following conclusions can be made,

In both brands the residual monomer content was initially high after processing but decreased with post cure treatments. Water immersion for one day at room temperature significantly decreased the residual monomer content. Hence, it can be inferred from the study that while processing the denture sufficient length of boiling phase should be given and the processed denture should be stored in water at least for one day before insertion in order to reduce the residual monomer content.

\section{REFERENCES}

1. Sadamori S A method of determining residual monomer in acrylic resin using methyl ethyl ketone Aust Dent J 1990; 35:509-13.

2. H. Tsuchiya Y Hoshino, K. Tajima, N Takagi. Leaching and cytotoxicity of formaldehyde and methyl methacrylate from acrylic resin denture base materials. J prosthet Dent 71:618-624, 1994

3. Pk Vallittu, V Miettinen P Alakuijala. Residual monomer content and its release into water from denture base materials. Dent Mater 1 1:338-342, 1995

4. Smith DC. Acrylic denture base- mechanical evaluation of dental polymethylmethacrylate. BrDent J11:9-17, 1961.

5. JA Nunes de mello,K O Braun etal. Reducing the negative effects of chemical polishing in acrylic resins by use of an additional cycle of polymerization.J Prosthet Dent 2003;89:598-602.

6. J.Shim,D C Watts Residual monomer concentration in denture base acrylic resin after an additional, soft liner heat cure cycle.Dent Mat.15(1999) P 296300

7. V Jerolimov, R Huggett, SC Brooks, JF Bates, Dr odont. The effect of variations in the polymer/monomer mixing ratios on residual monomer levels and flexural properties of denture base materials. Quint Dent Tech 9: 431-434 1985.

8. ISO 1567 Dentistry-Denture base polymers, Berlin: Beuth;2000

9. Robert $\mathrm{G}$ craig. Restorative dental materials ed:9th pg 508 Mosby 1993

10. ANUSAVICE KJ .Phillips, science of dental materials. W..Saunders; 2003. p.721-75 